\title{
Is Cystatin C Useful for the Detection and the Estimation of Low Glomerular Filtration Rate in Heart Transplant Patients?
}

\author{
Pierre Delanaye, ${ }^{1,6}$ Eric Nellessen, ${ }^{2}$ Etienne Cavalier, ${ }^{3}$ Gisèle Depas, ${ }^{4}$ Stéphanie Grosch, ${ }^{1}$ \\ Jean-Olivier Defraigne, ${ }^{5}$ Jean-Paul Chapelle, ${ }^{3}$ Jean-Marie Krzesinski, ${ }^{1}$ and Patrizio Lancellotti ${ }^{2}$
}

\begin{abstract}
Although previously studied in patients with chronic kidney disease, there is less data for the use of cystatin $\mathrm{C}$ and cystatin C-based formulas in heart transplant recipients. The ability of creatinine and cystatin $\mathrm{C}$ to detect renal failure (glomerular filtration rate [GFR] below $60 \mathrm{~mL} / \mathrm{min} / 1.73 \mathrm{~m}^{2}$ ) in heart transplant patients has been compared. The accuracy and precision of a creatinine-based formula (Modification of Diet in Renal Disease [MDRD]) versus a cystatin C-based formula (Rule's formula) to estimate GFR have also been studied. GFR was measured using the ${ }^{51} \mathrm{Cr}$ ethylenediamine tetraacetic acid tracer in 27 patients. There was no significant difference between GFR and the reciprocal of creatinine or cystatin C. Receiver operating characteristic curves for cystatin C and creatinine were similar. Both formulas were well correlated with the GFR. The bias of the cystatin C-based was significantly better than one of the MDRD formula, but the standard deviation appeared better for the MDRD formula (bias of $+3.9 \mathrm{~mL} / \mathrm{min} / 1.73 \mathrm{~m}^{2}$ versus $+12 \mathrm{~mL} / \mathrm{min} / 1.73 \mathrm{~m}^{2}$ and SD of 8.5 versus 11.6, respectively). Plasma cystatin C has no clear advantage over serum creatinine to detect renal failure in heart transplanted patients.
\end{abstract}

Keywords: Glomerular filtration rate, Cystatin C, Creatinine, Modification of Diet in Renal Disease.

(Transplantation 2007;83: 641-644)

$\mathrm{C}$ hronic renal failure is a common complication in heart transplant patients (1-3). Serum creatinine is the classical marker used to detect renal failure. However, this marker has clear limitations because of serum concentration variations according to muscle mass and tubular secretion (3-5). Plasma cystatin $\mathrm{C}$ is presented as a new marker of glomerular filtration rate (GFR) $(6,7)$. Notably, its plasma concentration has been shown to be independent of the muscular mass (8). Even if it remains controversial, several authors have described the superiority of plasma cystatin $\mathrm{C}$ over serum creatinine to detect renal failure (9-11). The goal of this study was to compare the interest of creatinine and cystatin $\mathrm{C}$ to detect renal failure in a population of heart transplant patients. Moreover, we have recently shown in

\footnotetext{
${ }^{1}$ Department of Nephrology, University of Liège, CHU, Sart Tilman, Liège, Belgium.

${ }^{2}$ Department of Cardiology, University of Liège, CHU, Sart Tilman, Liège, Belgium.

${ }^{3}$ Department of Clinical Chemistry, University of Liège, CHU, Sart Tilman, Liège, Belgium.

${ }^{4}$ Department of Nuclear Medicine, University of Liège, CHU, Sart Tilman, Liège, Belgium.

${ }^{5}$ Department of Cardiovascular Surgery, University of Liège, CHU, Sart Tilman, Liège, Belgium.

${ }^{6}$ Address correspondence to: Pierre Delanaye, M.D., Service de Dialyse, CHU Sart Tilman, 4000 Liège, Belgium.

E-mail: pierre_delanaye@yahoo.fr

Received 8 August 2006. Revision requested 31 October 2006.

Accepted 9 November 2006.

Copyright $\odot 2007$ by Lippincott Williams \& Wilkins

ISSN 0041-1337/07/8305-641

DOI: 10.1097/01.tp.0000253746.30273.cd
}

the same cohort of patients that the Modification of Diet in Renal Disease (MDRD) formula was the best of the creatininebased formulae to estimate GFR (12). Here, the MDRD formula was compared with a new cystatin C-based formula for the estimation of GFR (13).

The study population consisted of 27 white patients. The exclusion criteria were age $<15$ years and a body mass index $>35 \mathrm{~kg} / \mathrm{m}^{2}$. The reference method for GFR measurement was based on plasma clearance of ${ }^{51} \mathrm{Cr}$-ethylenediamine tetraacetic acid (EDTA) (14). Results were corrected by body surface area (15). Serum creatinine was measured with the kinetic rate-blanked compensated creatinine Jaffé method on Modular (Roche Diagnostics; reference values: $<1.21 \mathrm{mg} / \mathrm{dL}$ for the men and $<1.02 \mathrm{mg} / \mathrm{dL}$ for the women) (16). Plasma cystatin $\mathrm{C}$ was measured by a particle-enhanced nephelometric immunoassay (Dade Behring) (17). A value of cystatin C $<1$ $\mathrm{mg} / \mathrm{L}$ may be considered as normal in the general population (18).

The abbreviated MDRD formula used was:

$$
\begin{aligned}
& \mathrm{GFR}_{\mathrm{MDRD}} \\
& 0.742(\text { if female })
\end{aligned}
$$

Rule et al. have recently elaborated a specific cystatin C-based formula for transplanted patients. Two hundred and six transplanted patients have been observed in this study, including 30 heart transplant patients (13).

$$
\mathrm{GFR}_{\mathrm{CC}}=76.6 \times \text { cystatin }^{-1.16}
$$

The plasma markers used to detect renal failure were 
compared by correlation analysis and the receiver operating characteristic curves methods. The area under the curves was calculated to detect a GFR below $60 \mathrm{~mL} / \mathrm{min} / 1.73 \mathrm{~m}^{2}$. A coefficient of correlation between the estimated GFR (by creatinine or cystatin-based formula) and the measured GFR was calculated. A Bland and Altman analysis was performed. The bias was defined as the mean of the differences between the predicted and measured GFR. The standard deviations of the mean differences between measured and estimated GFR reflect the precision of the estimation. Formulae accuracy was determined by the percentage of the estimated GFR within $30 \%$ of the measured GFR. Statistical analyses were performed using MedCalc (MedCalc Software, Mariakerke, Belgium).

GFR measurement was performed in 27 white heart transplant patients (five women, 22 men). The clinical characteristics of the population were described previously (12). All patients had normal thyroid function. Among these 27 patients, 24 (89\%) had a GFR lower than $60 \mathrm{~mL} / \mathrm{min} / 1.73 \mathrm{~m}^{2}$.

After this first determination, the GFR was measured again at least 10 months later in 22 patients. The mean GFR 10 months later remained stable for those 22 patients. All isotopic GFR measurements (49) were pooled and their mean value was $39 \pm 15 \mathrm{~mL} / \mathrm{min} / 1.73 \mathrm{~m}^{2}$. A significant correlation between the GFR and the reciprocal of creatinine and cystatin $\mathrm{C}(\mathrm{r}=0.75, P<0.0001$ and $\mathrm{r}=0.66, P<0.0001$, respectively) was found. There was no difference between these correlations (Fig. 1).

To detect a GFR less than $60 \mathrm{~mL} / \mathrm{min} / 1.73 \mathrm{~m}^{2}$, the area under the curve was 0.86 for the creatinine and 0.83 for the cystatin C. The difference was not significant (Fig. 2). The creatinine value that gave the best sensitivity-specificity was $1.32 \mathrm{mg} / \mathrm{dL}$ (sensitivity of $72.7 \%$, specificity of $100 \%$ ). For the cystatin C, the value was $1.51 \mathrm{mg} / \mathrm{L}$ (sensitivity of $81.1 \%$, specificity of $83.3 \%)$.

Both MDRD and Rule formulae were moderately correlated with GFR ( $r=0.83$ and $r=0.66$, respectively, no statistical difference). The coefficients of determinations $\left(\mathrm{r}^{2}\right)$ were also relatively low (0.69 and 0.44 , respectively). The Bland and Altman analyses are given in Figure 3. The precision of the MDRD formula is linked to the SD of the mean difference. The precision of the MDRD formula was statistically better than the Rule formula (SD 8.5 versus 11.6, $P=0.033$ ). Nevertheless, the bias of the Rule cystatin-based formula was smaller than in the MDRD formula $(+3.9 \mathrm{~mL} / \mathrm{min}$ versus $+12 \mathrm{~mL} / \mathrm{min}$, respectively, $P=0.0002$ ). The GFR estimated with the MDRD formula was found within 30\% measured GFR in $43 \%$ cases, whereas the percentages were $67 \%$ for the GFR estimated by the cystatin-based formula $(P=0.029)$.

Given the high prevalence of C-reactive protein, the detection of reduced GFR is of great importance in the heart transplant population $(2,3)$. In this study, plasma cystatin C had no clear advantage over serum creatinine to detect renal failure. Nevertheless, for the estimation of GFR, the cystatin C-based equation could have some advantages over the MDRD equation.

Serum creatinine has a poor sensitivity to detect renal failure in the general population $(5,19)$. This marker may be even less accurate in heart transplant recipients because this population has a reduced muscular mass, notably because of chronic therapy by corticosteroids $(4,20,21)$. Regarding transplant populations, Tomlanovich et al. have also shown
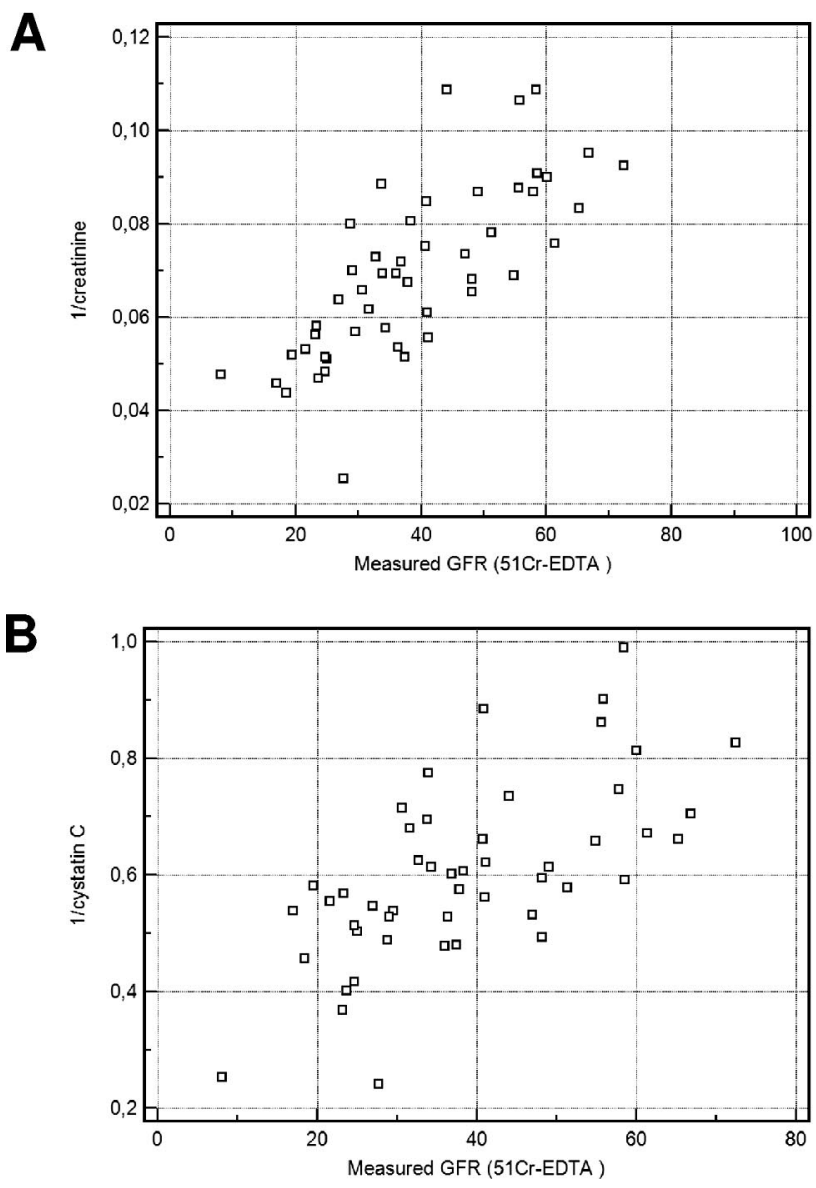

FIGURE 1. Correlations between measured GFR (by ${ }^{51} \mathrm{Cr}$-EDTA plasmatic clearance) and the reciprocal of creatinine $(A)$ and the reciprocal of cystatin $C(B) .(A) r=0.75$ $P<0.0001$. (B) $\mathrm{r}=0.66 P<0.0001$.

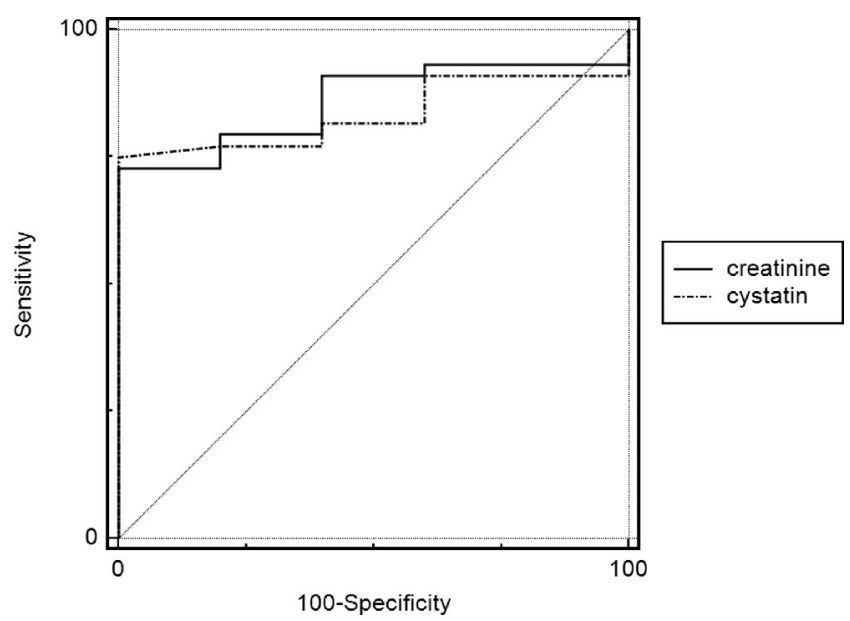

FIGURE 2. Receiver operating characteristic curves for cystatin $\mathrm{C}$ and creatinine (cutoff value for $\mathrm{GFR}=60 \mathrm{~mL} / \mathrm{min}$ / $\left.1.73 \mathrm{~m}^{2}\right)$.

some degree of creatinine tubular hypersecretion, dependent on cyclosporine therapy (4). If the reference values of creatinine with our Jaffé method are considered, $63.6 \%$ of our patients with normal creatinine values had a GFR less than 60 

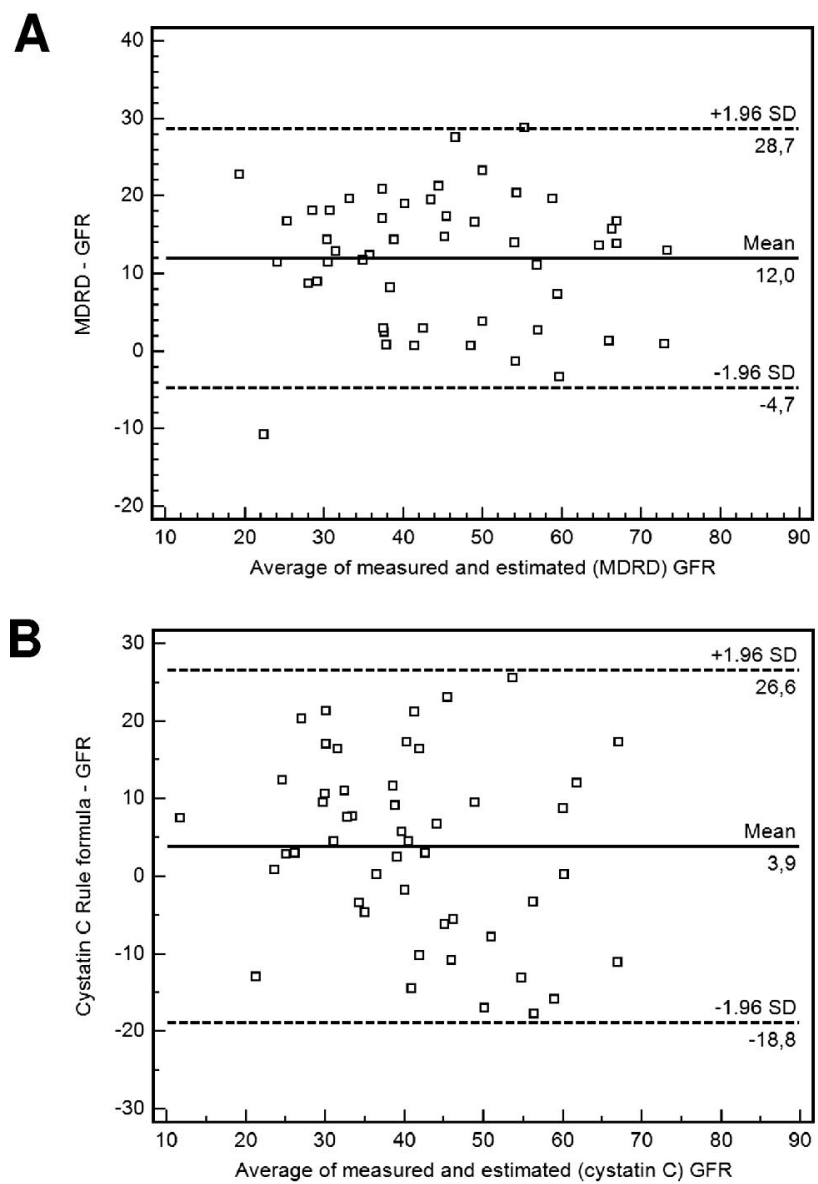

FIGURE 3. Bland and Altman plots for measured and estimated GFR MDRD (A) and Rule cystatin-based formula (B). The continuous line represents the mean difference between measured and estimated GFR, whereas the dashed lines represent the limits of agreement (mean difference \pm 2SD).

$\mathrm{mL} / \mathrm{min} / 1.73 \mathrm{~m}^{2}$. Nevertheless, the specificity of the serum creatinine was excellent.

The ability for plasma cystatin $\mathrm{C}$ to detect renal failure was not better than for serum creatinine. This can be explained by the lack of specificity of the cystatin C. All patients, even those with a GFR greater than $60 \mathrm{~mL} / \mathrm{min} / 1.73 \mathrm{~m}^{2}$ had high cystatin Clevels. Two arguments are proposed to explain these results. Firstly, some factors can interfere with cystatin C concentrations (dysthyroidism, smoking, weight) $(22,23)$. Maybe more important in the context of transplantation, some authors have suggested that corticoids can induce an increase of cystatin $\mathrm{C}$ concentration independently of any GFR changes $(24,25)$. This fact is still debated (26). However, in our patients, the cystatin $\mathrm{C}$ value that gives the best sensitivity-specificity rate was $1.51 \mathrm{mg} / \mathrm{dL}$, which is higher than the maximal normal value obtained in a normal population (18). The second explanation that may explain the lack of superiority of cystatin C may be linked to the range of GFR in our population. The majority of our patients had a GFR less than $60 \mathrm{~mL} / \mathrm{min} / 1.73 \mathrm{~m}^{2}$, although cystatin $\mathrm{C}$ is thought to be superior especially to detect a GFR between 60 and $80 \mathrm{~mL} /$ $\min / 1.73 \mathrm{~m}^{2}(11,27)$.

For the estimation of GFR, the Kidney/Disease Out- comes Quality Initiative (K/DOQI) guidelines recommend the use of creatinine-based formula and, among these, favor to the MDRD formula (19). However, we have recently shown that MDRD precision and accuracy are less in heart transplanted patients than in other populations (12). Recently, Rule et al. have elaborated a new cystatin-based formula from a large transplanted population. With the formula of Rule et al., the bias and the accuracy of the cystatin Cformula were significantly better than those of the MDRD. However, the precision reflected by the standard deviation and the correlation with GFR of the Rule formula was poor. Why this lack of precision? First, as we have already shown, cystatin C concentrations may be influenced by corticoids therapy. Our population was not homogeneous in term of corticotherapy, as $27 \%$ of our patients were corticoid-free. Moreover, the percentage of patients not treated by corticoids in the Rule study was not given. Secondly, the lack of precision of the cystatin C-based equations may be linked to the different assays for the cystatin $\mathrm{C}$ measurement and varied calibrations. Indeed, as it is the case with the creatinine, lack of precision or lack of calibration in the measurement of cystatin C will have great repercussions on the precision of cystatin C-based formulae (27-29). As for creatinine (30), harmonization and better precision are thus needed for the measurement of plasma cystatin C.

There are limitations to our study. Our sample was rather small. However, as we have already shown (12), the GFR range of our population appeared quite representative of the GFR range in the global heart transplanted population. Of importance, the conclusions of our study remained similar when statistics were limited to the first 27 patients and to the 22 patients who had had two GFR measurements (data not shown).

Plasma cystatin $C$ was not better than serum creatinine for detecting renal failure in a representative population of heart transplant patients. Nevertheless, if the serum creatinine of a heart transplant patient was abnormally high, one can conclude that this patient had a GFR less than $60 \mathrm{~mL} /$ $\min / 1.73 \mathrm{~m}^{2}$. In fact, with our creatinine assay, a value more than $1.32 \mathrm{mg} / \mathrm{dL}$ had a specificity of $100 \%$ to detect renal failure (and a sensitivity of $72.7 \%$ ). With our cystatin C assay, a value more than $1.01 \mathrm{mg} / \mathrm{L}$ had a sensitivity of $100 \%$ but a very low specificity. In other words, if the plasma cystatin C was in the normal range, then the patient had a GFR of at least $60 \mathrm{~mL} / \mathrm{min} / 1.73 \mathrm{~m}^{2}$. The bias and the accuracy (but not the precision) of the cystatin C-based formula were better than those of the MDRD formula. These preliminary data have to be confirmed on a larger sample. If a precise GFR is needed in clinical practice or studies with heart transplant patients, we do recommend the use of a reference method measurement.

\section{ACIKNOWLEDGIMENTS}

We want to thank Mrs. Rosalie Bonmariage for her help in the redaction of the manuscript. This work is dedicated to the memory of Dr. Jean-Claude Demoulin, who devoted a large part of his medical career to caring for heart transplant patients.

\section{REFERENCES}

1. Herlitz H, Lindelow B. Renal failure following cardiac transplantation. Nephrol Dial Transplant 2000; 15: 311.

2. Lindelow B, Bergh CH, Herlitz H, Waagstein F. Predictors and evolu- 
tion of renal function during 9 years following heart transplantation. J Am Soc Nephrol 2000; 11: 951.

3. Wilkinson AH, Cohen DJ. Renal failure in the recipients of nonrenal solid organ transplants. J Am Soc Nephrol 1999; 10: 1136.

4. Tomlanovich S, Golbetz H, Perlroth M, et al. Limitations of creatinine in quantifying the severity of cyclosporine-induced chronic nephropathy. Am J Kidney Dis 1986; 8: 332.

5. Perrone RD, Madias NE, Levey AS. Serum creatinine as an index of renal function: new insights into old concepts. Clin Chem 1992; 38: 1933.

6. Grubb A. Diagnostic value of analysis of cystatin $\mathrm{C}$ and protein $\mathrm{HC}$ in biological fluids. Clin Nephrol 1992; 38: S20-S27.

7. Tenstad O, Roald AB, Grubb A, Aukland K. Renal handling of radiolabelled human cystatin C in the rat. Scand J Clin Lab Invest 1996; 56 : 409.

8. Vinge E, Lindergard B, Nilsson-Ehle P, Grubb A. Relationships among serum cystatin $\mathrm{C}$, serum creatinine, lean tissue mass and glomerular filtration rate in healthy adults. Scand J Clin Lab Invest 1999; 59: 587.

9. Perkins BA, Nelson RG, Ostrander BE, et al. Detection of renal function decline in patients with diabetes and normal or elevated GFR by serial measurements of serum cystatin C concentration: results of a 4-year follow-up study. J Am Soc Nephrol 2005; 16: 1404.

10. O'Riordan SE, Webb MC, Stowe HJ, et al. Cystatin Cimproves the detection of mild renal dysfunction in older patients. Ann Clin Biochem 2003; 40: 648.

11. Dharnidharka VR, Kwon C, Stevens G. Serum cystatin C is superior to serum creatinine as a marker of kidney function: a meta-analysis. Am J Kidney Dis 2002; 40: 221.

12. Delanaye P, Nellessen E, Grosch S, et al. Creatinine-based formulae for the estimation of glomerular filtration rate in heart transplant recipients. Clin Transplant 2006; 20: 596.

13. Rule AD, Bergstralh EJ, Slezak JM, et al. Glomerular filtration rate estimated by cystatin $\mathrm{C}$ among different clinical presentations. Kidney Int 2006; 69: 399.

14. Chantler C, Garnett ES, Parsons V, Veall N. Glomerular filtration rate measurement in man by the single injection methods using ${ }^{51} \mathrm{Cr}$ EDTA. Clin Sci 1969; 37: 169.

15. Du Bois D, Du Bois E. A formula to estimate the approximative surface area if height and weight be known. Arch Intern Med 1916; 17: 863.

16. Mazzachi BC, Peake MJ, Ehrhardt V. Reference range and method comparison studies for enzymatic and Jaffe creatinine assays in plasma and serum and early morning urine. Clin Lab 2000; 46: 53.

17. Finney H, Newman DJ, Gruber W, et al. Initial evaluation of cystatin C measurement by particle-enhanced immunonephelometry on the Behring nephelometer systems (BNA, BN II). Clin Chem 1997; 43: 1016.

18. Galteau MM, Guyon M, Gueguen R, Siest G. Determination of serum cystatin C: biological variation and reference values. Clin Chem Lab Med 2001; 39: 850.

19. K/DOQI clinical practice guidelines for chronic kidney disease: evaluation, classification, and stratification. Am J Kidney Dis 2002; 39: S1.

20. Mariat C, Alamartine E, Afiani A, et al. Predicting glomerular filtration rate in kidney transplantation: are the K/DOQI guidelines applicable? Am J Transplant 2005; 5: 2698.

21. Kasiske BL. Creatinine excretion after renal transplantation. Transplantation 1989; 48: 424.

22. Fricker M, Wiesli P, Brandle M, et al. Impact of thyroid dysfunction on serum cystatin C. Kidney Int 2003; 63: 1944.

23. Knight EL, Verhave JC, Spiegelman D, et al. Factors influencing serum cystatin $\mathrm{C}$ levels other than renal function and the impact on renal function measurement. Kidney Int 2004; 65: 1416.

24. Risch L, Huber AR. Glucocorticoids and increased serum cystatin C concentrations. Clin Chim Acta 2002; 320: 133.

25. Bjarnadottir M, Grubb A, Olafsson I. Promoter-mediated, dexamethasone-induced increase in cystatin C production by HeLa cells. Scand J Clin Lab Invest 1995; 55: 617.

26. Bokenkamp A, van Wijk JA, Lentze MJ, Stoffel-Wagner B. Effect of corticosteroid therapy on serum cystatin $\mathrm{C}$ and beta2-microglobulin concentrations. Clin Chem 2002; 48: 1123.

27. Newman DJ. Cystatin C. Ann Clin Biochem 2002; 39: 89.

28. Delanaye P, Cavalier E, Chapelle JP, Krzesinski JM. Importance of the creatinine calibration in the estimation of GFR by MDRD equation. Nephrol Dial Transplant 2006; 21: 1130.

29. Delanaye P, Cavalier E, Krzesinski JM, Chapelle JP. Why the MDRD equation should not be used in patients with normal renal function (and normal creatinine values)? Clin Nephrol 2006; 66: 147.

30. Myers GL, Miller WG, Coresh J, et al. Recommendations for improving serum creatinine measurement: a report from the Laboratory Working Group of the National Kidney Disease Education Program. Clin Chem 2006; 52: 5 . 